\title{
Breaking-Wave Induced Transient Pore Pressure in a Sandy Seabed: Flume Modeling and Observations
}

\author{
Changfei Li ${ }^{1,2}$, Fuping Gao ${ }^{1,2, *(D)}$ and Lijing Yang ${ }^{1,2}$ \\ 1 Institute of Mechanics, Chinese Academy of Sciences, Beijing 100190, China; lichangfei@imech.ac.cn (C.L.); \\ yanglijing@imech.ac.cn (L.Y.) \\ 2 School of Engineering Science, University of Chinese Academy of Sciences, Beijing 100049, China \\ * Correspondence: fpgao@imech.ac.cn
}

check for

updates

Citation: Li, C.; Gao, F.; Yang, L. Breaking-Wave Induced Transient Pore Pressure in a Sandy Seabed: Flume Modeling and Observations. J. Mar. Sci. Eng. 2021, 9, 160. https:// doi.org/10.3390/jmse9020160

Academic Editor: Rafael J. Bergillos Received: 23 November 2020

Accepted: 3 February 2021

Published: 5 February 202

Publisher's Note: MDPI stays neutral with regard to jurisdictional claims in published maps and institutional affiliations.

Copyright: (c) 2021 by the authors. Licensee MDPI, Basel, Switzerland. This article is an open access article distributed under the terms and conditions of the Creative Commons Attribution (CC BY) license (https:// creativecommons.org/licenses/by/ $4.0 /)$.

\begin{abstract}
Previous studies on wave-induced pore pressure in a porous seabed mainly focused on non-breaking regular waves, e.g., Airy linear waves or Stokes non-linear waves. In this study, breaking-wave induced pore pressure response in a sandy seabed was physically simulated with a large wave flume. The breaking-wave was generated by superimposing a series of longer waves onto the foregoing shorter waves at a specified location. Water surface elevations and the corresponding pore pressure in the process of wave breaking were measured simultaneously at three typical locations, i.e., at the rear, just at, and in front of the wave breaking location. Based on test results, characterization parameters are proposed for the wave surface elevations and the corresponding pore-pressures. Flume observations indicate that the wave height was greatly diminished during wave breaking, which further affected the pore-pressure responses. Moreover, the measured values of the characteristic time parameters for the breaking-wave induced pore-pressure are larger than those for the free surface elevation of breaking-waves. Under the action of incipient-breaking or broken waves, the measured values of the amplitude of transient pore-pressures are generally smaller than the predicted results with the analytical solution by Yamamoto et al. (1978) for non-breaking regular waves with equivalent values of characteristic wave height and wave period.
\end{abstract}

Keywords: breaking wave; pore pressure; sandy seabed; flume observation

\section{Introduction}

Numerous failures of subsea structures have been reported as a result of the waveinduced seabed liquefaction or the reduction of soil strength of the seabed, e.g., lateral instability, sinking/uplifting of submarine pipelines [1-4], and instability of various types of offshore foundations [5-9]. As such, an appropriate evaluation for wave-induced porepressure responses in the seabed is vital in the practices of ocean and coastal engineering.

Since the 1970s, wave induced pore-pressure responses in a porous seabed have been investigated intensively, including analytical predictions [10-12], numerical modeling [13-15], and experimental observations [16-18]. From previous studies on the wave-seabed interaction $[8,19,20]$, one can recognize that most of the existing studies predominantly focused on the seabed responses under non-breaking regular waves.

In actual ocean environments, progressive waves may break while propagating towards shallow waters or in the mid-ocean as long as the wave amplitude is sufficient. The breaking-wave (also termed as "breaker") usually presents irregular and complex shapes. In the past few decades, flume experiments have been conducted to observe the breaking process of progressive waves [21-30]. Galvin [21] sorted the breaker type from films of wide range of laboratory conditions. The breaker type can be generally classified as spilling, plunging, collapsing, and surging, which is closely correlated with Iribarren number. Basco and Asce [22] developed a qualitative description of the breaking process. The classic spilling and plunging breakers were found to have similar initial breaking motions but at different scales. Two primary vortex motions were identified, i.e., a plunger vortex 
and a surface roller. Ting and Kirby [25] experimentally investigated the dynamics of surf zone turbulence in a strong plunging breaker. The results showed that turbulence under a plunging breaker was dominated by large-scale motions and was related to its wave condition. Chang and Liu [26] measured the flow field of breaking-waves with the Particle Image Velocimetry (PIV) technique. It was observed that the fluid particle velocity at the tip of the overturning jet could reach 1.68 times of the phase velocity predicted with the linear wave theory. Calabrese et al. [28] conducted a series of flume tests on the interaction between waves and submerged barriers and proposed a first parameterization of breaker types considering both wave and structure characteristics. Moragues et al. [29] identified the types of wave breaker on a 1:10 slope under regular waves based on the flume observations and added four types of wave breaker to Galvin's classification [21]. Corvaro et al. [30] performed flume experiments to study the wave damping induced by a porous bed and confirmed that the wave dissipation due to wave breaking was dominant over any other phenomena. As for the numerical modeling, Lin and Liu [31] developed a numerical model to investigate the evolution of a wave train, shoaling and breaking in the surf zone. Their model indicated that the pressure distribution under the spilling breaker was almost hydrostatic, where both the mean vorticity and turbulence intensity induced by the spilling breaker were very weak. Zhang and Liu [32] numerically studied the dynamic processes of bore propagation over a uniform slope. The weak bore would not break, while the strong bore would break as a plunger before it reaches the still-water shoreline. Lakehal and Liovic [33] reproduced the "weak plunger" on a beach with constant slope by means of large-eddy and interface simulation. The transport of turbulent kinetic energy was found to be shoreward along with the roller and seaward with the undertow, the air entrainment post-plunger impact was a highly dissipative process. Zijlema et al. [34] provided a complete description of the numerical algorithms of the Simulating WAves till SHore (SWASH) model for simulating wave fields and rapidly varied flows in coastal waters. It was found that the SWASH model yields a realistic representation of the observed frequency spectra for various boundary conditions, e.g., irregular waves breaking on a bar-trough beach profile, or in a barred surf zone.

In addition to the aforementioned investigations on the breaking process of progressive waves from the perspective of fluids, the seabed responses under breaking-waves have also attracted increasing attention. Jeng and Zhang [35] employed an integrated threedimensional poro-elastic model to evaluate the breaking-wave induced seabed liquefaction potential with a case study on the surf zones at Gold Coast in Australia. Their numerical results showed that the magnitude of pore pressures in the seabed under non-breaking waves is slightly greater than that under breaking-waves due to the effect of wave energy dissipation, which affects the corresponding liquefaction depth. Later, Ulker et al. [36] proposed a finite element model to investigate the breaking-wave induced soil responses around a caisson breakwater. Ye et al. [37] further numerically investigated the breaking wave-breakwater-seabed interactions, indicating that the effects of breaking-waves on the pore-pressure are significant near the seabed surface. It should be noticed that the existing studies on breaking-wave induced pore-pressure responses were mainly limited to numerical simulations, and experimental observations are still quite scarce. Moreover, the parameter correlation between breaking-waves and the corresponding pore-pressure responses in the seabed has not been well established.

In the present study, a series of flume tests was conducted to investigate the transient pore-pressure responses in a fine-grained sand-bed under breaking-waves. The nonbreaking regular wave induced pore-pressure response was also measured for comparison. Based on flume observations, several characteristic parameters are identified to describe the water surface elevations of breaking-waves and the corresponding transient pore-pressures in the seabed. The flume test results on breaking-wave induced pore-pressure responses are further compared with the existing analytical solution for non-breaking regular waves. 


\section{Physical Modeling}

\subsection{Experimental Setup}

The breaking wave-seabed interactions were physically modeled in a large wave flume at the Institute of Mechanics, Chinese Academy of Sciences. The major frame of the flume is $52.0 \mathrm{~m}$ in length, $1.0 \mathrm{~m}$ in width, and $1.5 \mathrm{~m}$ in depth. In the middle of the flume, a soil-box of $5.0 \mathrm{~m}$ (length) $\times 0.6 \mathrm{~m}$ (depth) $\times 1.0 \mathrm{~m}$ (width) was constructed for the seabed modeling, as shown in Figure 1. A piston-type wave maker was installed at the inlet of the flume for generating various types of progressive waves, e.g., breaking-waves or linear/nonlinear regular waves. A sloping beach-type wave absorber located at the end of the flume has a high efficiency of wave absorption, whose wave reflection coefficient is generally less than $5.0 \%$.

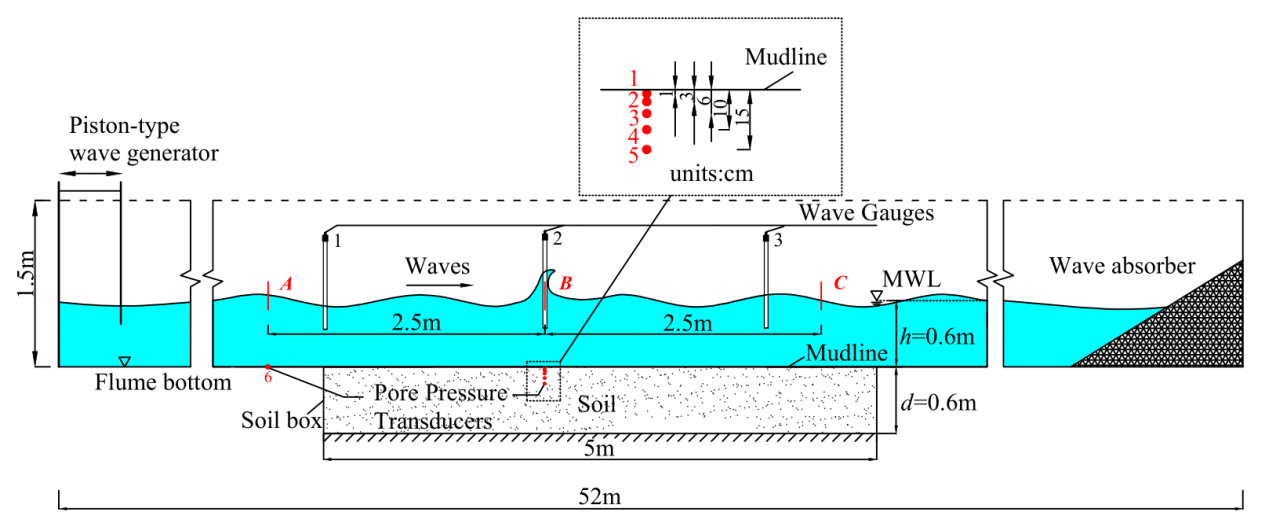

Figure 1. Schematic diagram of the flume modeling of breaking-wave induced pore-pressure in a fine-sand bed.

A fine-sand bed was prepared with a sand-raining device. Figure 2 gives the particle size distribution curve of the soil, and the main physical properties of the soil are listed in Table 1. In the wave flume tests, the surface of the sand bed was plane and the water depth $(h)$ was kept constant $(h=0.6 \mathrm{~m})$. Six miniature pore-pressure transducers (PPTs) were utilized to measure the wave induced pore-pressure in the soil (PPT 1 5, at Location B) as well as the pressure fluctuation at the flume bottom (PPT 6, at Location A), as detailed in Figure 1. The probe of the PPT is $5.0 \mathrm{~mm}$ in diameter and $17.0 \mathrm{~mm}$ in length, with the measuring range of $0-20 \mathrm{kPa}$ and accuracy of $0.2 \%$. To simultaneously monitor the free water surface elevation, three wave gauges (WGs) were utilized down-wave from, just above and up-wave from Location B (see Figure 1). The signals of WGs and PPTs were multichannel synchronous sampled via the data acquisition card (NI USB-6363) with a sampling frequency of $25 \mathrm{~Hz}$.

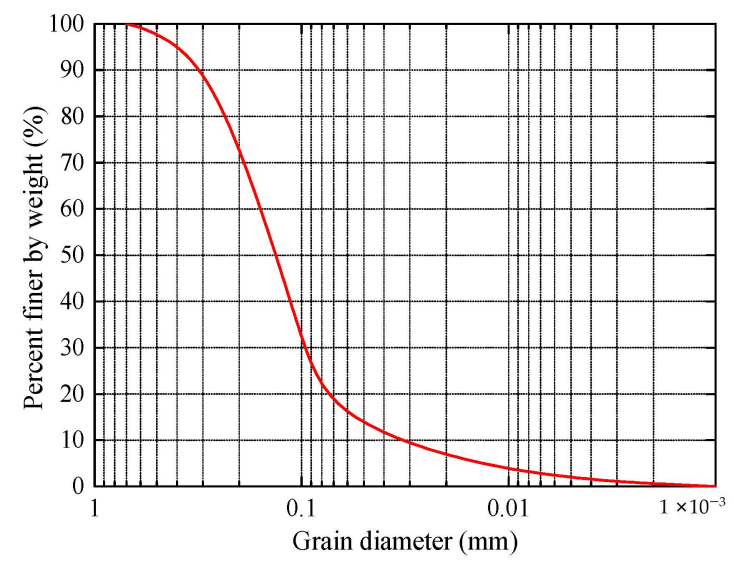

Figure 2. Grain size distribution curve of the test fine-sand. 
Table 1. Main physical properties of the test fine-sand.

\begin{tabular}{cc}
\hline Soil Properties & Values \\
\hline Mean size of grains $d_{50}(\mathrm{~mm})$ & 0.12 \\
Effective size of grains $d_{10}(\mathrm{~mm})$ & 0.03 \\
Specific gravity of grains $s$ & 2.65 \\
Buoyant unit weight $\gamma^{\prime}\left(\mathrm{N} / \mathrm{m}^{3}\right)$ & $9.70 \times 10^{3}$ \\
Coefficient of permeability $k_{\mathrm{s}}(\mathrm{m} / \mathrm{s})$ & $9.60 \times 10^{-5}$ \\
Degree of saturation $S_{\mathrm{r}}$ & 0.993 \\
Void ratio $e$ & 0.67 \\
Relative density $D_{\mathrm{r}}$ & 0.62 \\
Shear modulus $G(\mathrm{~Pa})$ & $23.8 \times 10^{6}$ \\
Poisson's ratio $v$ & 0.30 \\
\hline
\end{tabular}

\subsection{Test Procedures}

The test procedure for breaking-wave induced pore-pressure responses was adopted as follows:

(1) The wave flume and the centrally located soil box were firstly emptied and cleaned. The argil-covers of the PPTs were fully saturated to ensure being free of air.

(2) The de-aired PPTs were then installed at various depths in the soil $(z=1.0,3.0,6.0$, $10.0,15.0 \mathrm{~cm}$ at Location $\mathrm{B} ; z=0$ at Location $\mathrm{A}$ ) with the support of the fixing racks (see Figure 1).

(3) The fine-sand bed was carefully prepared by employing the sand-raining technique, i.e., the dry sand particles in a reciprocating trolley were rained into the clean water in the soil box. With such sand-raining technique, the bed was generally homogeneous and saturated. The surface of the sand-bed was then leveled off smoothly with a scraper.

(4) The wave flume was slowly filled with water to a given depth $(h=0.6 \mathrm{~m})$.

(5) The piston-type wave maker was then activated and the progressive waves were generated. Meanwhile, the multichannel synchronous sampling system was started to simultaneously measure the free surface elevation of progressive waves and transient pore-pressure in the sand-bed with WGs and PPTs, respectively.

\subsection{Generation of Breaking-Waves}

In the coastal surf zones, the wave breaking is commonly caused by the shoaling effect as the progressive waves propagating towards the shore. As well known, the similarity law for gravitational waves is Froude number. The frequent occurrence of wave breaking phenomenon in shallow waters is due to the lower group velocity there. The distinction in the breaker type is not always clear out, and the relative parameter ranges are necessarily inexact [38]. In brief, the criterion for the steepest wave is that the water particle velocity at the crest is just equal to the wave celerity, therefore any further increase in particle velocity would cause an instability of the progressive waves, i.e., Stokes' criterion.

Generally, two methods exist for generating breaking-waves under laboratory conditions: (1) Preparing a sloping bed to make the regular waves propagate towards shallow waters (e.g., [21]), and (2) generating large-wave height waves in the relatively shallow water over a flat bed (e.g., [26]). These two methods both aim to generate waves with large wave steepness so that the progressive waves are more likely to lose stability. In the present physical modeling, the breaking-waves were generated by means of superimposing a series of longer waves with higher group velocities onto the proceeding shorter waves with lower group velocities. While the large-wavelength waves are catching up with the small-wavelength ones, the superposed wave broke suddenly. The prepared sand bed within the soil box was flat, which differs from the sloping bed condition in most previous simulations. Under such a condition, the plunging-type breaker was generated, which will be further discussed in Section 3.1.

Note that the wave breaking is a continuous process, and the point where the front face of the wave becomes vertical or the wave crest starts to curl over is usually defined as the 
initial breaking location in the previous observations [21,26]. In the present study, the breaking location refers to the point where the foregoing shorter waves were swallowed up by the following larger waves with higher speed and the air bubbles (white water) were observed.

The propagation velocity of the wave energy of a wave train is termed as the group velocity $\left(c_{\mathrm{g}}\right)$, which can be expressed as follows:

$$
c_{\mathrm{g}}=\frac{1}{2} n_{\mathrm{w}} c
$$

where $c$ is the phase velocity: $c=\omega / \lambda$, in which $\omega$ is the angular frequency $(\omega=2 \pi / T$, in which $T$ is the wave period), $\lambda$ is the wave number $(\lambda=2 \pi / L$, in which $L$ is the wavelength); the coefficient $n_{\mathrm{w}}$ is calculated with $n_{\mathrm{w}}=1+2 \lambda h / \sin \mathrm{h}(2 \lambda h)$. In physical terms, the group velocity is the speed of propagation of a finite group of waves as distinct from the speed of the individual waves themselves [38]. For shallow water waves (i.e., $h / L<1 / 20$ ), $n_{\mathrm{w}}=2$, while for deep water waves (i.e., $h / L>1 / 2), n_{\mathrm{w}}=1$.

Once the piston-type wave maker was activated, the shortest wave with the minimum wave period $T_{0}$ was firstly generated at time $t=0$. The time for this shortest wave with the lowest group velocity $c_{\mathrm{g} 0}$ propagating from the wave maker to the breaking location can be expressed as follows:

$$
t_{0}=\frac{l_{\mathrm{b}}}{c_{\mathrm{g} 0}}
$$

where $l_{\mathrm{b}}$ is the distance between the wave paddle and the specified breaking location. Note that the subscript " 0 " denotes the wave parameters for the shortest wave, i.e., $c_{\mathrm{g} 0}=n_{\mathrm{w} 0} c_{0} / 2, c_{0}=w_{0} / \lambda_{0}$, and $n_{\mathrm{w} 0}=1+2 \lambda_{0} h / \sin \mathrm{h}\left(2 \lambda_{0} h\right)$. Then, the wave maker keeps on generating several following longer waves with unchanged wave height $\left(H_{0}\right)$ but continuously increasing the wave period $\left(T_{\mathrm{i}}\right)$. Assuming the wave maker generates a following longer wave with wave period $T_{\mathrm{i}}$ at time $t_{\mathrm{i}}$, it would take a period of " $t_{0}-t_{\mathrm{i}}$ " for these waves propagating up to the breaking location:

$$
t_{0}-t_{\mathrm{i}}=\frac{l_{\mathrm{b}}}{c_{\mathrm{gi}}}
$$

Correspondingly, the subscript " $\mathrm{i}$ " denotes the wave parameters for the generated wave at the following time $t_{\mathrm{i}}$. Thus, the wave period of the following longer wave $\left(T_{\mathrm{i}}\right)$ at time $t_{\mathrm{i}}$ can be derived as follows:

$$
T_{\mathrm{i}}=\frac{\pi n_{\mathrm{wi}}\left(t_{0}-t_{\mathrm{i}}\right)}{\lambda_{\mathrm{i}} l_{\mathrm{b}}}
$$

On the basis of Equation (4) and the dispersion relationship $\omega^{2}=\lambda g \tan \mathrm{h} \lambda \mathrm{h}$, the wave periods of the following waves can be obtained. Therefore, all the generated waves with wave period $T_{\mathrm{i}}$ are superposed just at the breaking location. As illustrated in Figure 1, the progressive waves were controlled to break at three specified breaking locations, i.e., in front (Location A), just at (Location B), and at the rear (Location C) of the position of pore-pressure measurements with five PPTs (Location B). To conveniently distinguish the typical stages of breaking-wave generation, the following descriptions are adopted, i.e., the progressive wave upstream from the breaking location is described as in the stage of "non-breaking" (before wave breaking), the wave just breaking above the specified location as in the stage of "incipient-breaking", and the broken wave downstream from the breaking location as in the stage of "broken" (after wave breaking).

Test conditions for physical modeling of breaking-waves in the flume are summarized in Table 2, in which $H_{0}$ is the wave height of the shortest wave initially generated near the wave maker; $T_{0}$ is the corresponding wave period of the shortest wave; $t_{0}$ is calculated with Equation (2). Note that $H_{0}$ was kept constant for all the wave components near the wave paddle. Nevertheless, with the propagation of the wave series, the wave heights were gradually amplified until a breaking wave is generated due to the wave superposition 
effect. In Table 2, $H_{\mathrm{m}}$ and $T_{\mathrm{w}}$ are the characteristic wave height and the characteristic wave period of the free surface elevation induced by the breaking-wave for three typical breaking locations (i.e., Location A, B, or C), which was measured by WG 2 at Location B. The identifications of $H_{\mathrm{m}}$ and $T_{\mathrm{w}}$ are further detailed in Section 3.2

Table 2. Test conditions for physical modeling of breaking-waves in the flume *.

\begin{tabular}{|c|c|c|c|c|c|c|}
\hline Test Number & $H_{0}(\mathrm{~cm})$ & $T_{0}(\mathrm{~s})$ & $t_{0}(\mathrm{~s})$ & Breaking Location $/ l_{\mathrm{b}}(\mathrm{m})$ & $H_{\mathrm{m}}(\mathrm{cm})$ & $T_{\mathrm{w}}(\mathrm{s})$ \\
\hline $1-\mathrm{A}$ & 8.0 & 0.7 & 33.86 & Location A/18.5 & 15.68 & 1.92 \\
\hline $1-B$ & 8.0 & 0.7 & 38.43 & Location B/21.0 & 17.11 & 1.72 \\
\hline $1-\mathrm{C}$ & 8.0 & 0.7 & 43.01 & Location $\mathrm{C} / 23.5$ & 22.62 & 1.32 \\
\hline $2-\mathrm{A}$ & 8.0 & 0.9 & 25.72 & Location A/18.5 & 12.02 & 2.04 \\
\hline $2-B$ & 8.0 & 0.9 & 29.20 & Location B/21.0 & 20.09 & 1.60 \\
\hline $2-C$ & 8.0 & 0.9 & 32.67 & Location C/23.5 & 18.99 & 1.56 \\
\hline 3-A & 10.0 & 0.7 & 33.86 & Location A/18.5 & 14.06 & 2.0 \\
\hline 3-B & 10.0 & 0.7 & 38.43 & Location B/21.0 & 24.59 & 1.44 \\
\hline $3-C$ & 10.0 & 0.7 & 43.01 & Location C/23.5 & 24.09 & 1.52 \\
\hline
\end{tabular}

${ }^{*}$ Note: $H_{\mathrm{m}}$ and $T_{\mathrm{w}}$ were measured at Location $\mathrm{B}$.

\section{Results and Discussion}

\subsection{Elevations of the Free Water Surface of Breaking-Waves}

Figure 3 presents the typical snapshots of wave profiles in the process of wave breaking. To well distinguish the time intervals, the moment when the waves were photographed as Figure $3 a$ is set as $t=0$. As shown in Figure $3 a, b$, the foregoing shorter waves were superimposed by following longer waves (non-breaking). The crest of the superimposed wave finally became vertical and curled over (incipient-breaking, see Figure 3c). As the overturning jet translated to strike the oncoming trough, i.e., the wave crest collapsed and dropped onto the wave surface, an "air pocket" was clearly observed (see Figure 3d). Then, the trapped air-core was compressed, and numerous air-bubbles were generated within the broken wave surface, resulting in a "crashing" sound concurrently. A notable plunger vortex was created by the sustained forward particle motion at the crest of the overturning wave and the rearward trough motion. Meanwhile, a surface roller was observed, which is similar to the roller of a hydraulic jump. The plunger vortex translated horizontally and pushed on the oncoming wave trough to create a secondary wave disturbance (see Figure 3e). The main vortex along the wave front diffuses rapidly into the interior of the wave after breaking, as the eddies on the surface become more viscous; the wave energy was transformed into turbulent kinetic energy (see Figure 3f), which would further affect the pore-pressure in the underlying sand-bed. In the process of wave breaking, the rotational flow would be induced, which differs from the irrotational flow for non-breaking regular waves. For wave shoaling on a coastline, the breaker type depends on the wave steepness and the beach slope. Under the flat sand-bed condition, the plunging-type breaker is prone to occurrence as described before. The wave breaking phenomena were basically consistent with the previous observations by Basco and Asce [22].

The time series of water surface elevations $(\eta)$ measured at different locations for the breaking-wave (the Test 1-B, listed in Table 2) are given in Figure 4: (a) Before wave breaking (non-breaking wave, measured with WG 1, see Figure 1); (b) at wave breaking (incipientbreaking wave, with WG 2); and (c) after wave breaking (broken wave, with WG 3). As shown in Figure $4 a$, a series of waves was generated with the wave period increasing gradually. The wave height was gradually amplified due to the wave superposition, while the wave series propagating towards the designed breaking location. The relatively shorter wave series were followed by longer waves with a more significant oscillation magnitude than that of the foregoing waves (see Figure 4a). While with wave breaking (measured with WG 2, see Figure $4 \mathrm{~b}$ ), the shorter waves seemed to be swallowed up, evolving into a large incipientbreaking wave. After the wave breaking, the elevations of the free water surface were notably diminished (see Figure 4c) and appeared to be significantly disordered (see Figure 3d-f). Comparisons between Figure $4 \mathrm{a}-\mathrm{c}$ further illustrate that the oscillation magnitudes of the waves were greatly reduced (from $H_{\mathrm{m}}=17.11$ to $9.34 \mathrm{~cm}$ ) due to the wave breaking. 


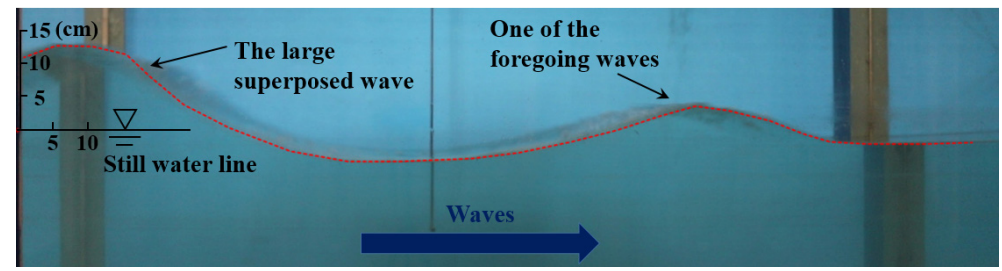

(a)

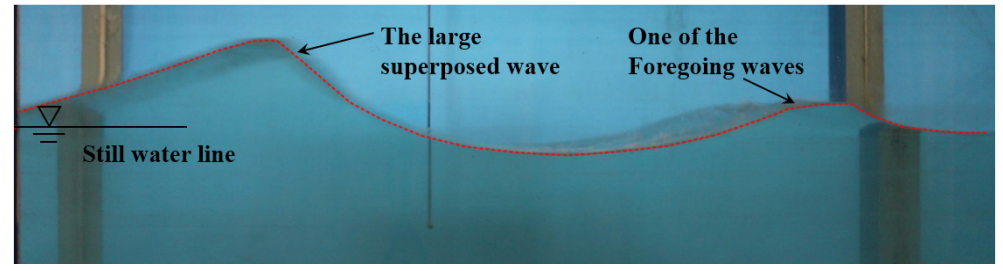

(b)

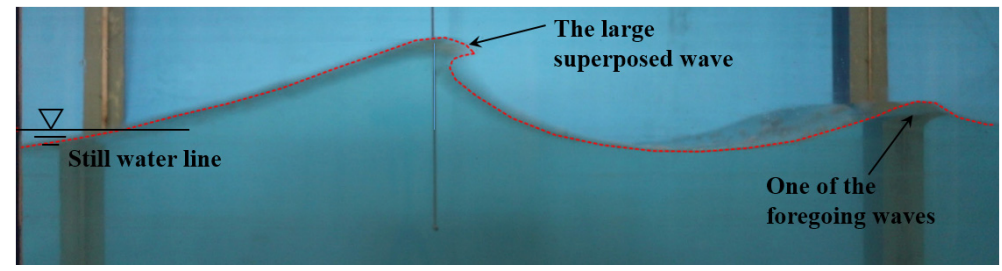

(c)

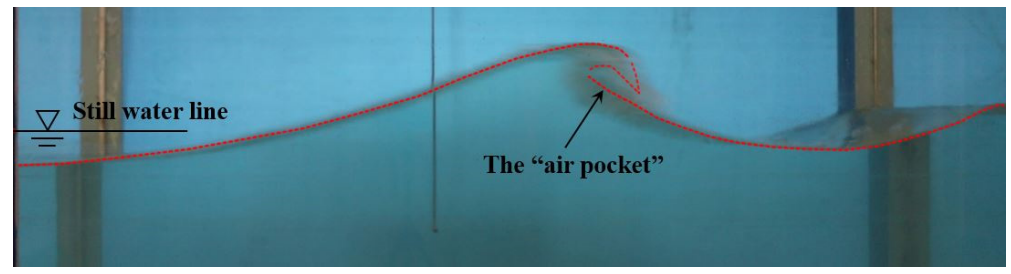

(d)

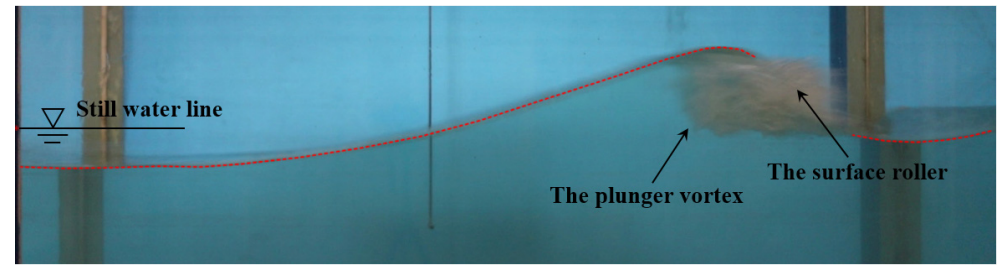

(e)

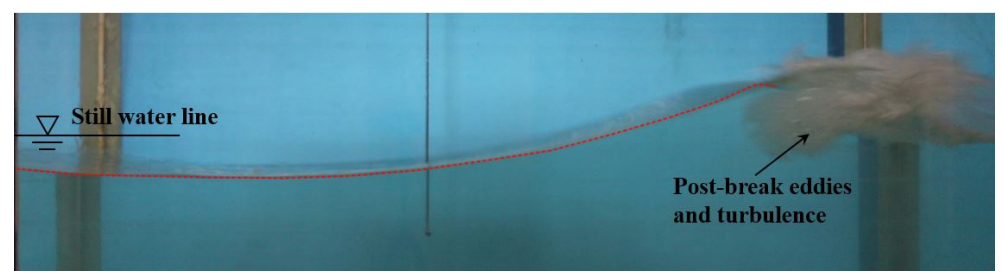

(f)

Figure 3. Typical snapshots of the wave profiles at (a) $t=0 ;(\mathbf{b}) t=0.2 \mathrm{~s}$; (c) $t=0.36 \mathrm{~s} ;(\mathbf{d}) t=0.52 \mathrm{~s}$; (e) $t=0.68 \mathrm{~s} ;(\mathbf{f}) t=0.84 \mathrm{~s}$. 


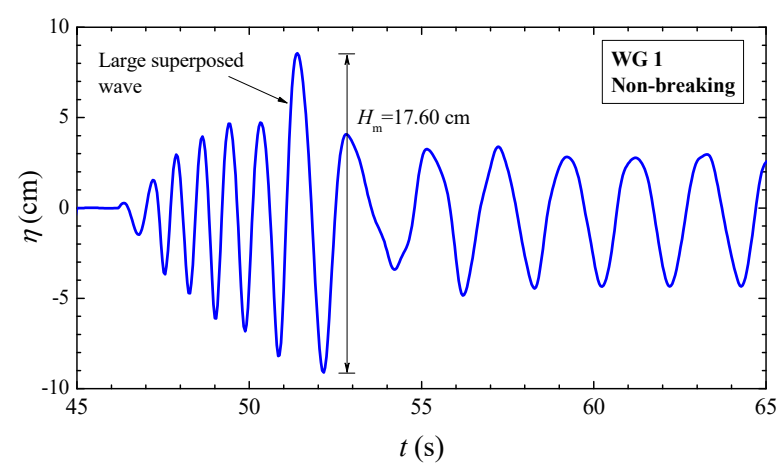

(a)

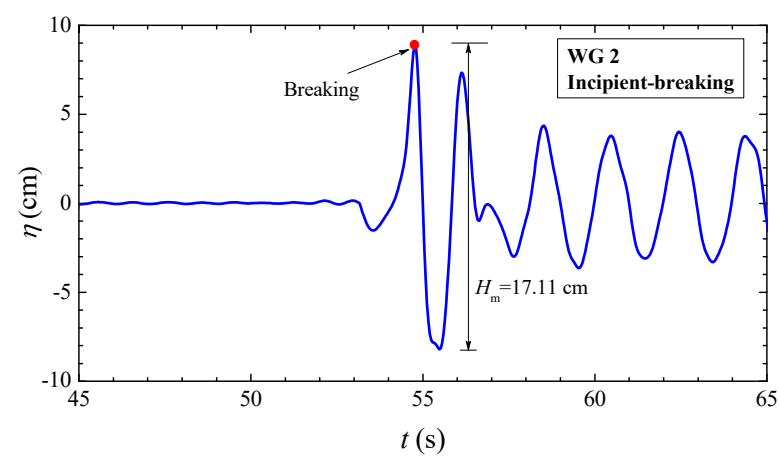

(b)

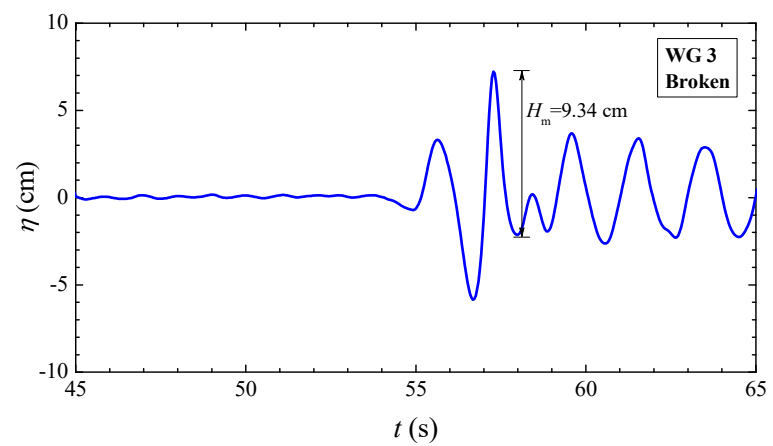

(c)

Figure 4. Time series of the water surface elevations $(\eta)$ measured: (a) In front of the breaking location (measured by wave gauge (WG) 1); (b) just at the breaking location (by WG 2); (c) at the rear of the breaking location (by WG 3).

\subsection{Pore-Pressure Responses: Under Breaking-Waves, and under Non-Breaking Regular Waves}

Under the action of breaking-waves, the wave pressure fluctuations at the surface of the bed $(p)$ were monitored by a pore-pressure transducer (PPT 6) installed at Location A (see Figure 1). Figure 5 gives the measured wave pressures just under (wave broke at Location A) and in front of the breaking location (wave broke at Location B or C). For the purpose of comparison, the expression $p / \gamma_{\mathrm{w}}\left(\gamma_{\mathrm{w}}\right.$ is the unit weight of the water, $\gamma_{\mathrm{w}}=9.8 \times 10^{3} \mathrm{~N} / \mathrm{m}^{3}$ ) is used to keep the same dimension with $\eta$. As expected, the short wave induced pressures on the bed surface before wave breaking were quite weak, while the longer wave induced pressures became more significant (see Figure $5 b, c$ ). While wave breaking, the wave induced pressure with a remarkable negative trough was detected on the sand-bed surface (see Figure 5a). As shown in Figure 5a, the wave pressure at the flume bottom just under the breaking-wave $(t=53 \mathrm{~s})$ is featured with a remarkably larger negative trough, which is different from that for non-breaking waves (see Figure $5 b, c$ ). 


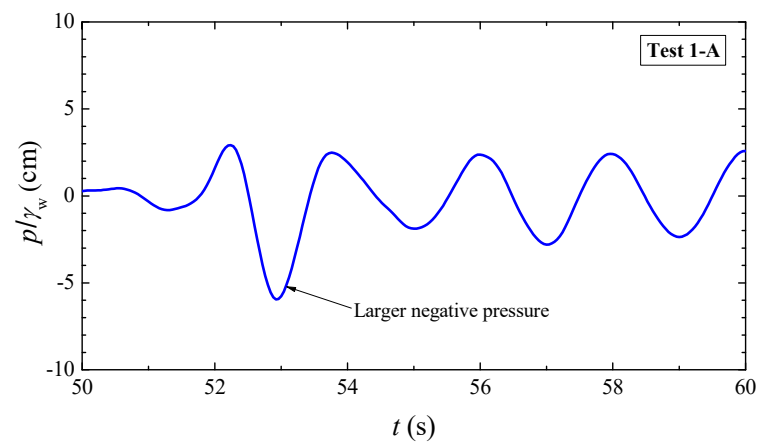

(a)

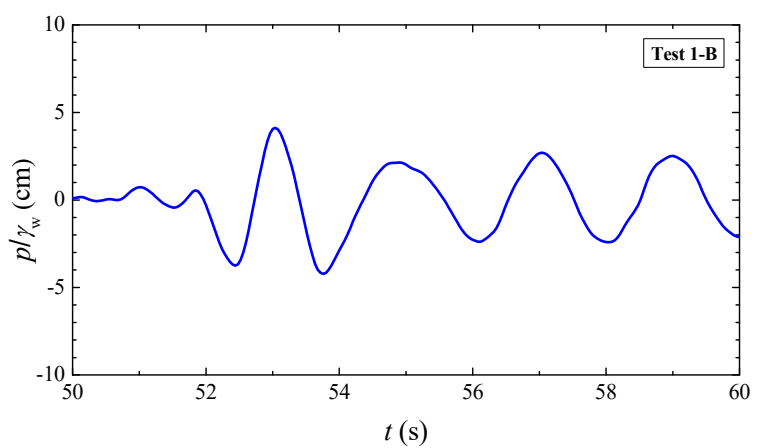

(b)

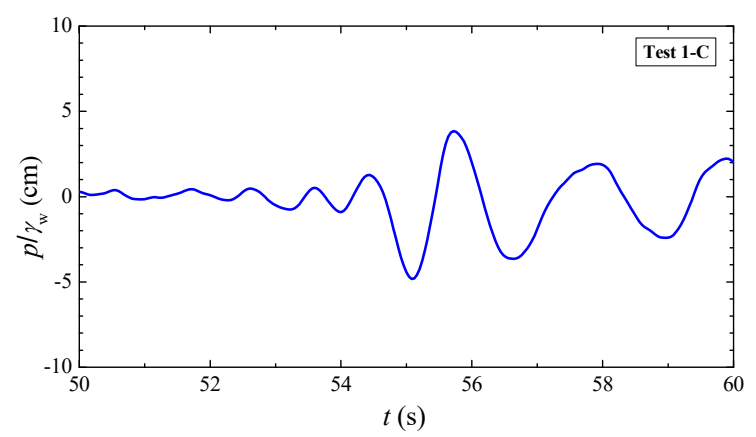

(c)

Figure 5. Wave-pressure fluctuations at the bottom of the flume measured at Location $A$ for the waves breaking at: (a) Location A (Test 1-A); (b) Location B (Test 1-B); and (c) Location C (Test 1-C).

Figure 6 gives the water surface elevation $(\eta)$ and the vertical distribution of pore-pressures $(p)$, which were simultaneously measured at Location B (see Figure 1) for three typical wave breaking locations. That is, Figure 6a shows the pore-pressure responses in the sand-bed at the rear of the wave breaking location (Location A, marked as "Test 1-A"); Figure 6b just at the wave breaking location (Location B, "Test 1-B"); and Figure $6 \mathrm{c}$ in front of the wave breaking location (Location C, “Test 1-C"). As shown in Figure 6, no excess pore-pressure accumulation was observed in the examined fine-sand. The amplitude of the wave-induced transient pore-pressure attenuated along the soil depth and an evident phase-lag was observed. For the relatively shorter wave series before wave breaking (e.g., $t=55 \mathrm{~s}$ to $57 \mathrm{~s}$ in Figure $6 \mathrm{c}$ ), the pore-pressure responses were weak even though the corresponding wave heights seemed notable. Both the wave profile and the wave induced pore-pressure presented an irregular variation due to wave superposition effects in the process of wave breaking at various locations (Location A, B, or C). After the wave breaking at Location A (see Figure 6a), a relatively lower wave crest and a remarkable trough of the free surface elevation $(\eta)$ were detected at Location B. 


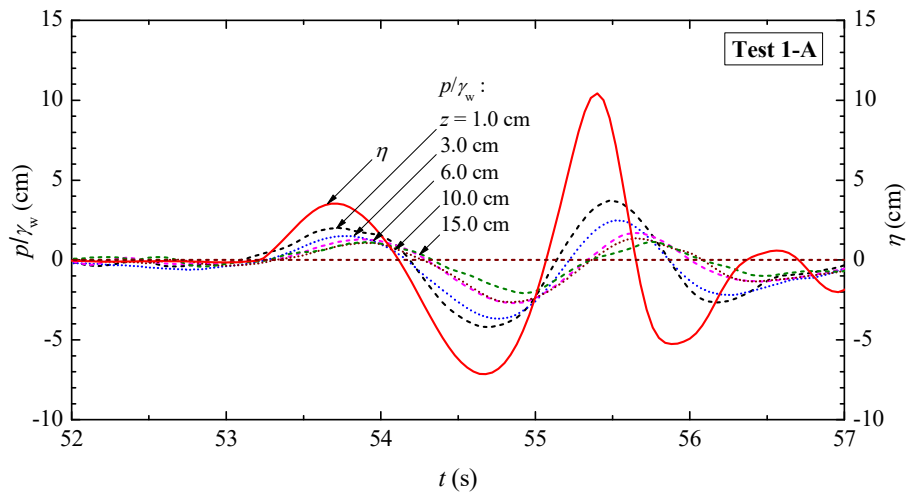

(a)

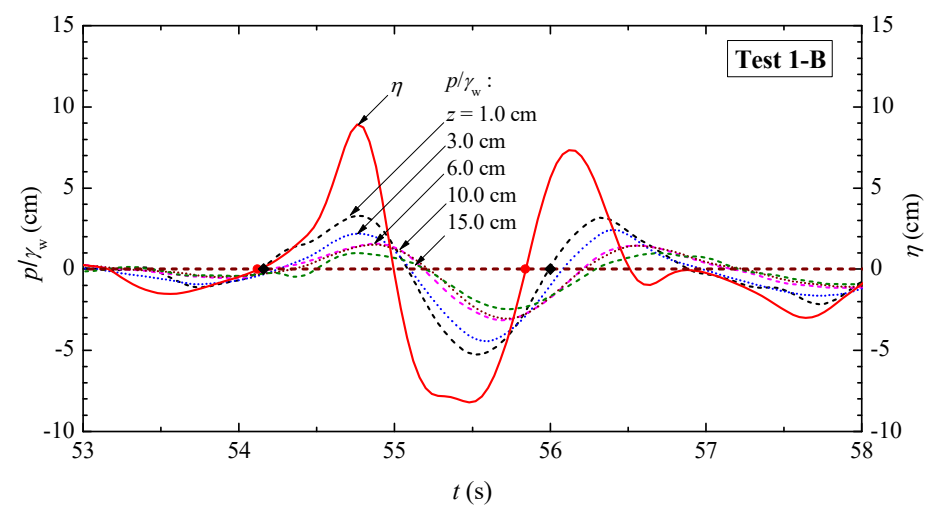

(b)

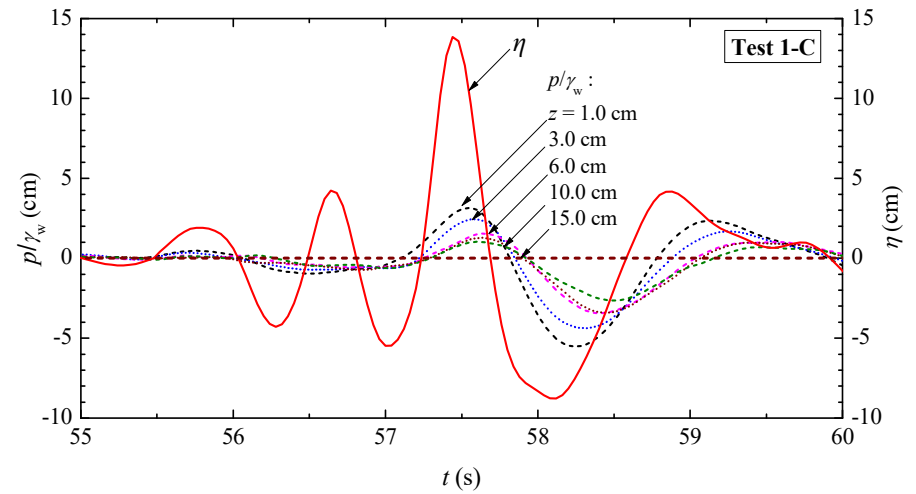

(c)

Figure 6. Time series of free water surface elevation $(\eta)$ and transient pore-pressure $(p)$ measured at Location B under the breaking-wave that occurred at (a) Location A (Test 1-A); (b) Location B (Test 1-B); and (c) Location C (Test 1-C).

For better understanding the superimposed waves and the pore-pressures in the process of wave breaking, it would be interesting and beneficial to examine their Fourier spectra in the frequency-domain. Based on the measured data for water surface elevations and the corresponding transient pore-pressures (see Figure 6), the Fourier spectra for the waves and those for the pore-pressures at various soil depths can be obtained as shown in Figure 7. As the expression $p / \gamma_{\mathrm{w}}$ has the same dimension with $\eta$ (i.e., $\mathrm{cm}$ ), the dimension 
of energy density $(E)$ in the wave spectrum can be consistent with that in the pore-pressure spectrum (i.e., $\mathrm{cm}^{2} / \mathrm{Hz}$ ). As shown in Figure $7 \mathrm{a}-\mathrm{c}$, as for the frequency-domain responses for the three typical breaking locations, the peak frequencies of the surface waves are generally larger than those of the pore-pressures. Meanwhile, the peak frequencies of the pore-pressures for various soil depths are basically identical. Compared with the case for the wave breaking location (Location $C$, see Figure $7 \mathrm{c}$ ) downstream from the measurement location (Location B), the high-frequency components of the surface waves were greatly cut down for the cases of broken waves (see Figure 7a) or incipient-breaking waves (Figure $7 \mathrm{~b}$ ). As can be imagined, the high-frequency components of the superimposing surface waves (e.g., $f>0.9 \mathrm{~Hz}$, see Figure $7 \mathrm{a}-\mathrm{c}$ ) were hardly detected by the PPTs, i.e., the spectral intensity for higher frequencies of pore-pressures was significantly reduced.

In the present study, the flume observations for the pore-pressure responses under nonbreaking regular waves were also carried out with the same fine-sand bed for comparison. The test procedures are similar with the descriptions in Section 2.2. The water depth $(h)$ and wave height $(H)$ were kept as $h=0.5 \mathrm{~m}$ and $H=0.13 \mathrm{~m}$, respectively, while the wave periods ( $T$ ) were varied, i.e., $T=1.2,1.5,1.8$, and $2.1 \mathrm{~s}$. Figure 8 a gives the typical time series of free surface elevation $(\eta)$ and the transient pore-pressures $(p)$ for the case of $T=1.2 \mathrm{~s}$. Both the wave profile and wave-induced pore-pressure presented quasi-sinusoidal variations. The amplitude-attenuation and phase-lag phenomena were also observed. Figure $8 \mathrm{~b}$ gives the vertical distributions of the non-dimensional pore-pressure amplitude $\left(|p| / \gamma_{\mathrm{w}} H\right.$, in which $|p|$ is the pore-pressure amplitude) for various wave periods. It is indicated that the pore-pressure amplitude increases with the increasing wave period from $T=1.2$ to $2.1 \mathrm{~s}$ (see Figure $8 \mathrm{~b}$ ).

To characterize (in the time-domain) breaking-wave profiles and the corresponding transient pore-pressure responses in a sand-bed, Figure 9 gives the sketch of the free surface elevation for the breaking-wave and the corresponding pore-pressure parameters, taking Test 1-C as an example:

- The characteristic wave period $\left(T_{\mathrm{w}}\right)$ is identified by the upward zero-crossing of $\eta$ (see Figure 9).

- The characteristic wave height $\left(H_{\mathrm{m}}\right)$ is the variation between the highest wave crest and the following wave trough within a complete wave period.

- Correspondingly, the characteristic period of the transient pore-pressure $\left(T_{\mathrm{p}}\right)$ and the oscillation magnitude of the transient pore-pressure $\left(p_{\mathrm{m}}\right)$ can also be identified.

- $\quad$ To describe the large wave-crest of the breaking wave and the corresponding porepressure, the time intervals between the upward zero-crossing and downward zerocrossing of $\eta$ and $p$ are defined as $t_{\mathrm{w}}$ and $t_{\mathrm{p}}$, respectively.

- The phase-lag between the pore-pressure peak and the wave crest could also be identified.

Such characteristic parameters can be defined for all the scenarios, i.e., before breaking (non breaking, as detailed in Figure 9), incipient-breaking, and after-breaking (broken), provided that the highest wave crest and the following wave trough of the free surface elevation $(\eta)$ are identified. Note that the time parameters of the transient pore-pressure $\left(t_{\mathrm{p}}\right.$ or $\left.T_{\mathrm{p}}\right)$ are almost equivalent for various soil depths under a certain test condition (see Figure 6). Figure 9 indicates that the oscillation profiles of the breaking-wave and the corresponding pore-pressure in the soil are both asymmetrical. Before the wave breaking, the amplitude of the large-wave crest $(\eta=13.85 \mathrm{~cm}$ at $t \approx 57.4 \mathrm{~s})$ is more significant than that of the large-wave trough $(\eta=-8.77 \mathrm{~cm}$ at $t \approx 58.1 \mathrm{~s})$. Nevertheless, the amplitude of the transient pore-pressure trough $\left(p / \gamma_{\mathrm{w}}=-5.52 \mathrm{~cm}\right.$ at $\left.t \approx 58.2 \mathrm{~s}\right)$ is more significant than that of the transient porepressure crest $\left(p / \gamma_{\mathrm{w}}=3.15 \mathrm{~cm}\right.$ at $\left.t \approx 57.6 \mathrm{~s}\right)$. Such spatial non-correspondence between the profiles of the waves and wave-induced pore-pressure was also observed in Figure 6b, which highlights the wave breaking effects on the transient pore-pressure responses.

Figure 10 gives the comparisons for the time parameters of the breaking-wave $\left(t_{\mathrm{w}}\right.$ and $\left.T_{\mathrm{w}}\right)$ and the corresponding pore-pressure in the sand-bed $\left(t_{\mathrm{p}}\right.$ and $\left.T_{\mathrm{p}}\right)$ for all the flume experiments listed in Table 2. As illustrated in Figure 10, the measured values of the above characteristic time parameters of the pore-pressure $\left(t_{\mathrm{p}}\right.$ and $\left.T_{\mathrm{p}}\right)$ are generally larger than those of the superimposing large waves $\left(t_{\mathrm{w}}\right.$ and $\left.T_{\mathrm{w}}\right)$. The data points of $T_{\mathrm{w}}$ vs. $T_{\mathrm{p}}$ lie within about $+20 \%$ error range 
from the $45^{\circ}$ solid line, while the data points of $t_{\mathrm{w}}$ vs. $t_{\mathrm{p}}$ fall between about $+20 \%$ and $+40 \%$. This may be attributed to the wave superposition effects during the wave breaking process: The superposition of such series of waves made the wave break and the porepressure response present more disordered. The PIV measurements of Chang and Liu [26] have also indicated that the number and locations of the breaking-wave induced vortices on the horizontal plane are random. Such temporally mismatched phenomena between the progressive waves and corresponding pore-pressures, i.e., $T_{\mathrm{w}} \neq T_{\mathrm{p}}$, are quite common for the case of random waves [39].

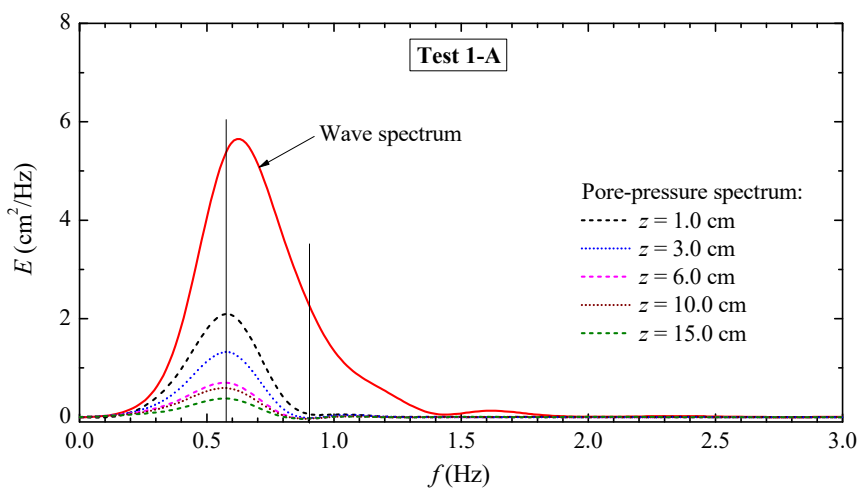

(a)

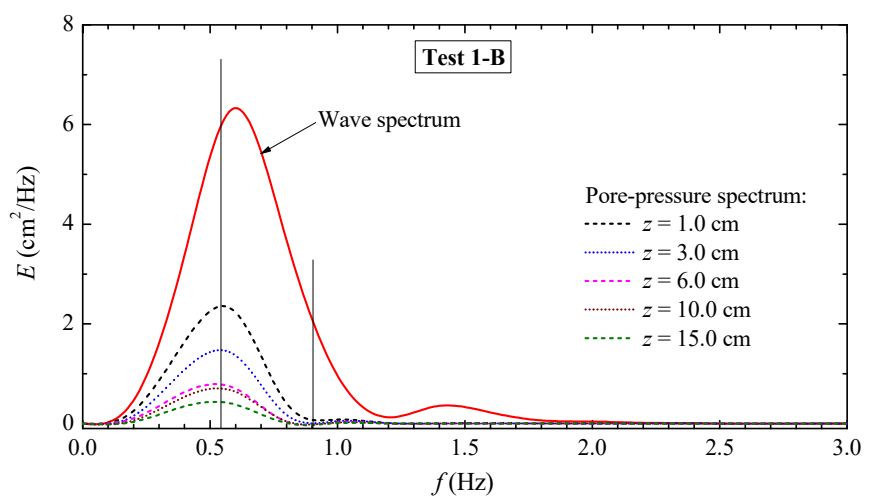

(b)

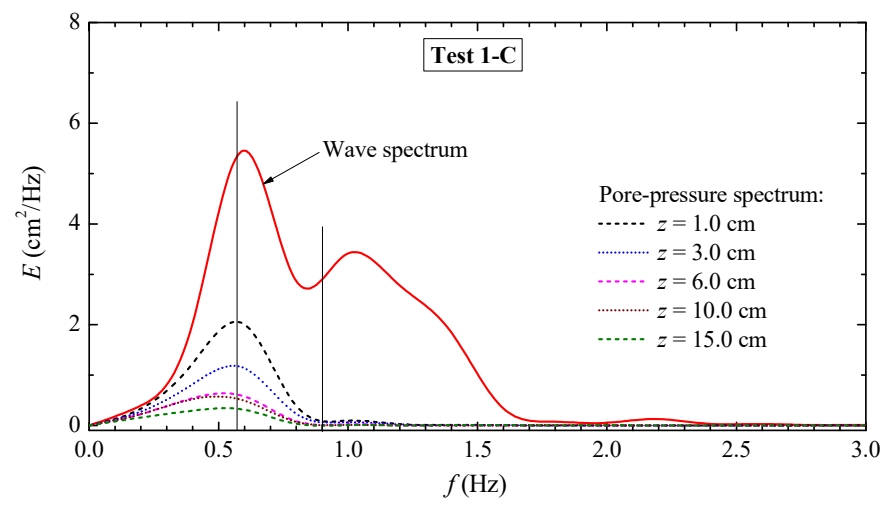

(c)

Figure 7. Fourier spectra for the waves and the corresponding pore-pressures based on the measured data shown in Figure 6: (a) The waves broke at Location A (Test 1-A); (b) at Location B (Test 1-B); and (c) at Location C (Test 1-C). 


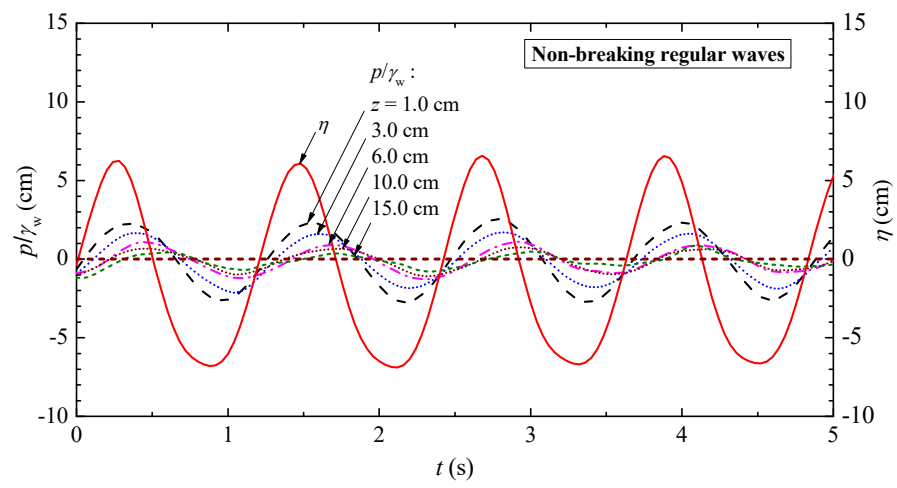

(a)

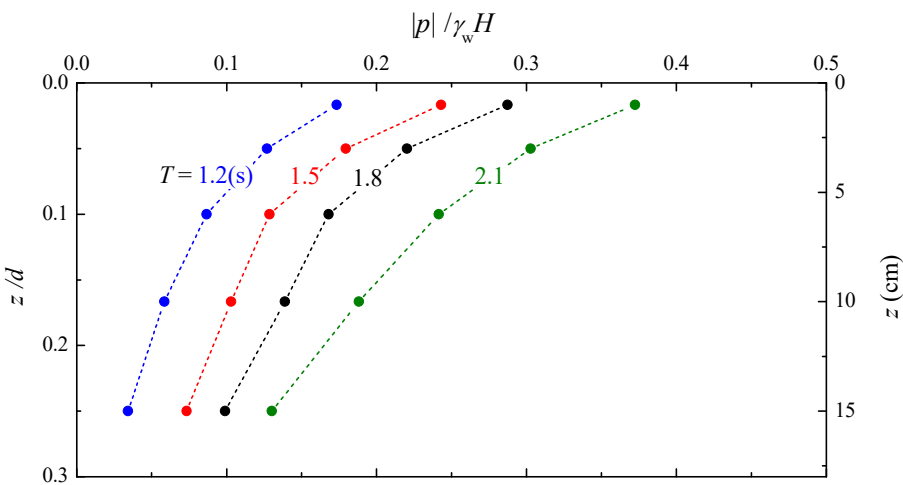

(b)

Figure 8. Flume observations for non-breaking regular wave induced pore-pressure responses: (a) Typical time series of free water surface elevation $(\eta)$ and transient pore-pressure $(p)$ for $T=1.2 \mathrm{~s}$;

(b) vertical distributions of pore-pressure amplitude for various wave periods.

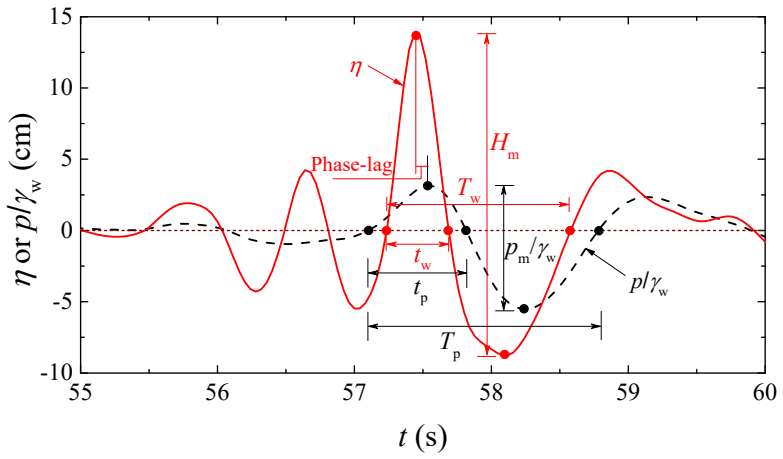

Figure 9. Characterization for the free surface elevation $(\eta)$ of the breaking-wave and the corresponding pore-pressure response $(p)$ in a sand-bed measured at Location B.

Figure 11 gives the vertical distributions of $p_{\mathrm{m}}$ under the breaking-wave series at the three typical breaking locations. Both the dimensional ( $p_{\mathrm{m}} / \gamma_{\mathrm{w}}$ vs. $z$ ) and non-dimensional forms $\left(p_{\mathrm{m}} / \gamma_{\mathrm{w}} H_{\mathrm{m}}\right.$ vs. $\left.z / d\right)$ are presented. Note again that all the pore-pressure responses were measured at Location B. As shown in Figure 11, the amplitude of transient pore-pressure attenuates with the soil depth and the pore-pressure gradient is more significant in the surface layer of the fine-sand bed. Figure 11a,c,e indicate that, compared with the broken case (test series " $\mathrm{A}$ "), the variation trend of $p_{\mathrm{m}}$ with the soil depth $(z)$ for the non-breaking case (test series " $\mathrm{C}^{\text {") }}$ is much closer to that of $p_{\mathrm{m}}$ for the incipient-breaking case (test series " $\mathrm{B}$ "), although a certain deviation may exist between the values of $H_{\mathrm{m}}$ for the non-breaking case and incipientbreaking case. The increasing or decreasing of $H_{\mathrm{m}}$ implies the randomness of the free surface 
elevation while wave breaking. Nevertheless, the magnitude of pore-pressure oscillation was reduced significantly after wave breaking. As shown in Figure $11 \mathrm{~b}, \mathrm{~d}, \mathrm{f}$, the variation trends of the non-dimensional oscillation magnitude of the transient pore-pressure $\left(p_{\mathrm{m}} / \gamma_{\mathrm{w}} H_{\mathrm{m}}\right)$ with the dimensionless soil depth $(z / d)$ for test series " $\mathrm{A}$ ", " $\mathrm{B}$ ", and " $\mathrm{C}$ " become much closer, which implies the significant effects of wave height $\left(H_{\mathrm{m}}\right)$ on the pore-pressure responses.

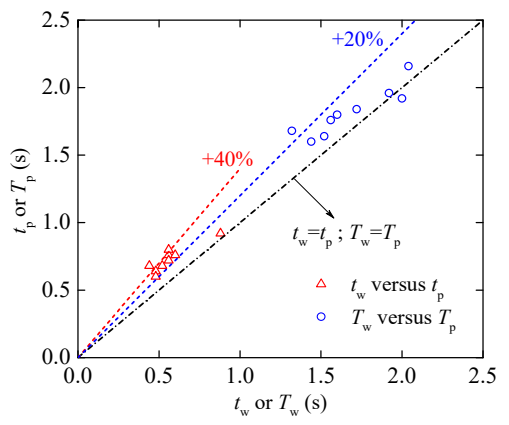

Figure 10. Time parameters of the breaking waves and the corresponding transient pore-pressure.

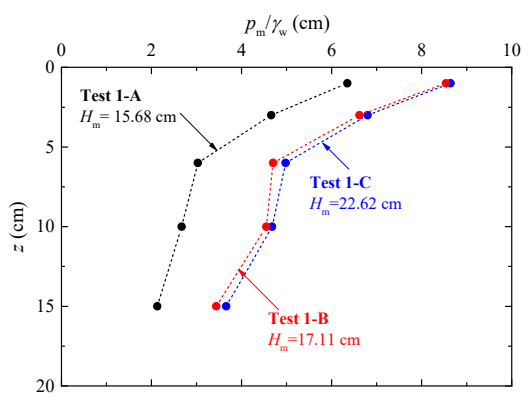

(a)

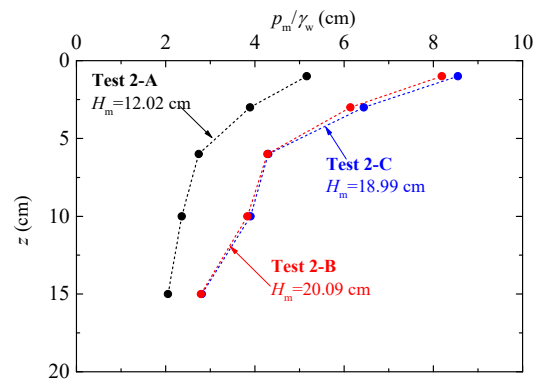

(c)

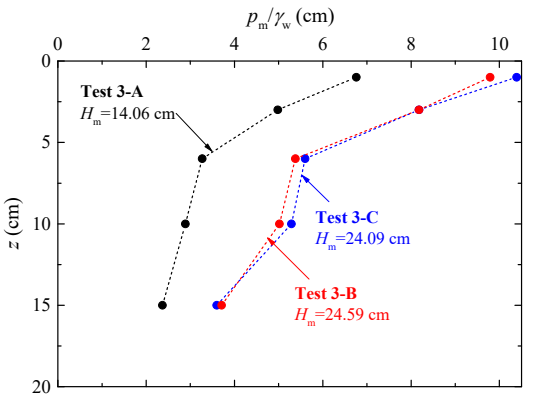

(e)

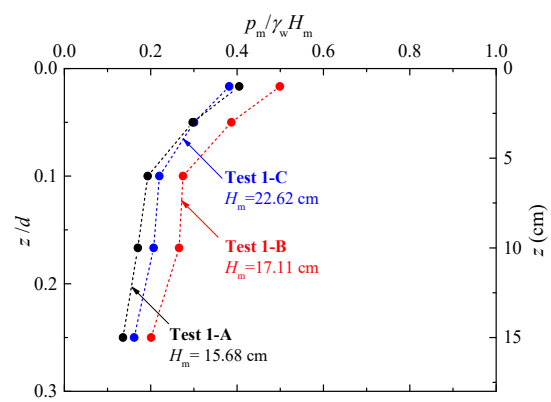

(b)

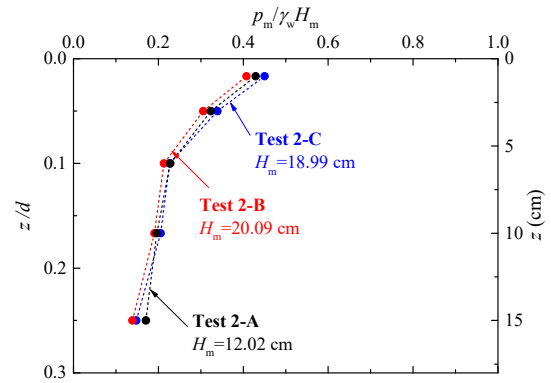

(d)

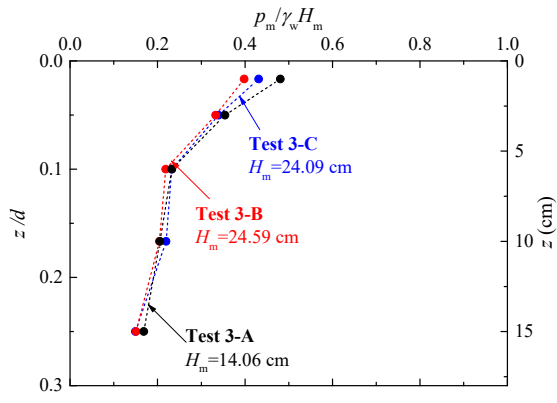

$(\mathbf{f})$

Figure 11. Vertical distributions of $p_{\mathrm{m}}$ measured at Location $\mathrm{B}$ under the breaking-wave for various test series in the dimensional ( $p_{\mathrm{m}} / \gamma_{\mathrm{w}}$ vs. $\left.z\right)$ and non-dimensional forms $\left(p_{\mathrm{m}} / \gamma_{\mathrm{w}} H_{\mathrm{m}}\right.$ vs. $\left.z / d\right):(\mathbf{a}, \mathbf{b})$ For Test 1 ; (c,d) for Test 2; and (e,f) for Test 3. 


\subsection{Comparison between Experimental Results and Analytical Predictions}

As aforementioned, previous theoretical models were predominantly limited to nonbreaking regular waves. Analytical predictions for the breaking-wave induced porepressure are still lacking at present. In this paper, the experimental results are compared with the analytical solution proposed by Yamamoto et al. [10], which has been widely adopted to predict the pore-pressure responses induced by non-breaking regular waves. The Yamamoto solution was derived on the basis of Biot's consolidation theory [40]. The basic assumptions were adopted as follows: (1) The seabed is regarded as an infinite, isotropic, and homogeneous poro-elastic medium, and the soil skeleton obeys Hooke's law; (2) the pore-fluid may contain air bubbles, thus the pore-fluid is compressible; and (3) the seepage of pore-fluid obeys Darcy's law. The difference between the soil responses under non-breaking regular waves and breaking-waves are examined via such comparison.

According to [10], the wave induced transient pore-pressure $p(z)$ can be expressed as:

$$
p(z)=P_{b}\left[(1-\alpha) \exp (-\lambda z)+\alpha \exp \left(-\lambda^{\prime} z\right)\right]
$$

where $P_{b}=p_{0-\mathrm{a}} \exp [i(\lambda x+\omega t)]$ is the wave pressure fluctuation at the sand-bed surface, in which $p_{0-\mathrm{a}}=0.5 \gamma_{\mathrm{w}} \mathrm{H} / \cosh (\lambda h)$ is the amplitude of $P_{b}$, and $i$ is the imaginary number. The expressions of $\alpha$ and $\lambda^{\prime}$ are as follows:

$$
\begin{aligned}
\alpha & =\frac{i m \omega^{\prime \prime}}{\left(1-\lambda^{\prime} / \lambda\right)+i(1+m) \omega^{\prime \prime}} \\
\left(\lambda^{\prime}\right)^{2} & =\lambda^{2}+i \frac{\gamma_{w}}{k_{s}} \omega\left(\frac{1-2 v}{2(1-v) G}+\frac{n}{K^{\prime}}\right)
\end{aligned}
$$

where $m=n G /\left(K^{\prime}(1-2 v)\right), K^{\prime}$ is the apparent bulk modulus of the pore-fluid, $G$ and $v$ are the shear modulus and the Poisson's ratio of the soil, respectively; $\omega^{\prime \prime}=\beta\left(\omega^{\prime} / \lambda^{2}\right)$, in which $\beta=(1-v) /(1-2 v), \omega^{\prime}=\omega / c^{\prime}, c^{\prime}=\frac{k_{s}}{\gamma_{w}} /\left(\frac{n}{K^{\prime}}+\frac{1-2 v}{2(1-v) G}\right)$ and $n$ is the soil porosity.

Figure 12 gives the comparisons of the vertical distributions of pore-pressure amplitude between experimental results and analytical solutions for the present test conditions. As the breaking-wave and the corresponding transient pore-pressures are essentially irregular, the input wave parameters for calculating the transient pore-pressure amplitude with Equation (5) are set as $T=T_{\mathrm{w}}$ and $H=H_{\mathrm{m}}$. The experimental data of transient pore-pressure amplitude are approximated as $|p|=p_{\mathrm{m}} / 2$. Note that all the input wave parameters for the analytical predictions with Equation (5) were measured at Location B with WG 2, which is consistent with the installation location of the PPTs. The test series are grouped for “Test C" (non-breaking)", “Test B" (incipient-breaking), and "Test C" (broken). As shown in Figure 12, the deviations between experimental results and analytical solutions present an increasing trend with the time development of the wave breaking process.

Figure 13 summarizes the comparisons of the transient pore-pressure amplitude between all of the measured experimental data and the corresponding analytical predictions under non-breaking regular waves and breaking-waves. Herein, $|p| / p_{0-\mathrm{a}}$ characterizes the relative magnitude of the transient pore-pressure amplitude at a certain soil depth $(|p|)$ to the calculated wave pressure amplitude at the mudline $\left(p_{0-\mathrm{a}}\right)$.

As shown in Figures 12 and 13, under the non-breaking regular wave, the analytical predictions of pore-pressure amplitude generally match well with the experimental data as expected. Nevertheless, under breaking waves, the pore-pressure responses are featured with various scenarios at different stages in the process of wave breaking. Before wave breaking, i.e., under the non-breaking but superposed large waves, the measured pore-pressures present to be random but still consistent with the analytical predictions to a certain extent, which is attributed to the irregular wave profiles. The wave height may be amplified due to the wave celerity difference between progressive waves but the wave period is also reduced. While the wave suddenly breaks (incipient-breaking wave), the breaking-waves would trap and compress the air under the wave surface, i.e., the "white water" was generated, leading 
to the dissipation of wave energy and reduction of wave pressure acting on the sand-bed surface. Therefore, the measured transient pore-pressure amplitudes tend to be smaller than the analytical solutions. As for the after-breaking stage (broken wave), the measured pore-pressure amplitudes were generally smaller than the values predicted with the Yamamoto solution.

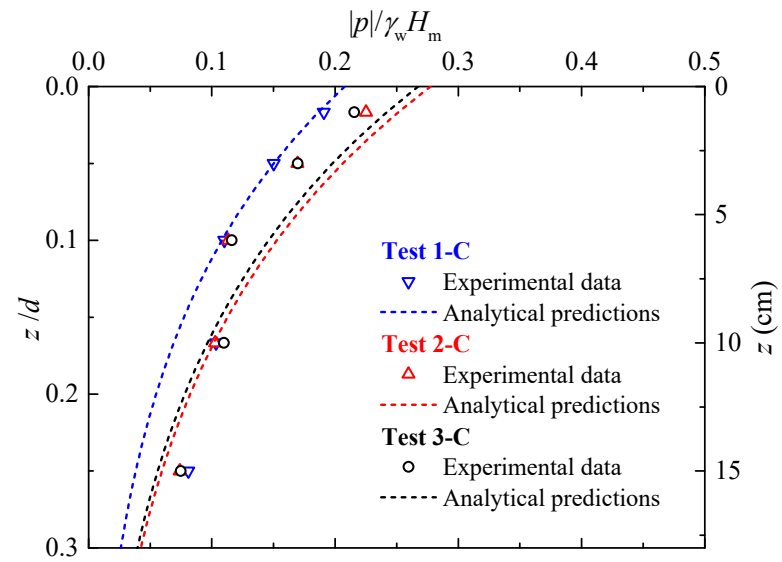

(a)

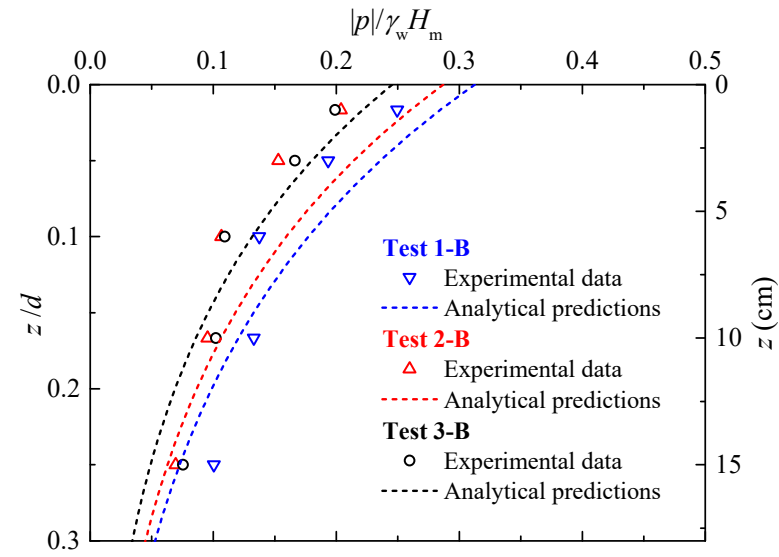

(b)

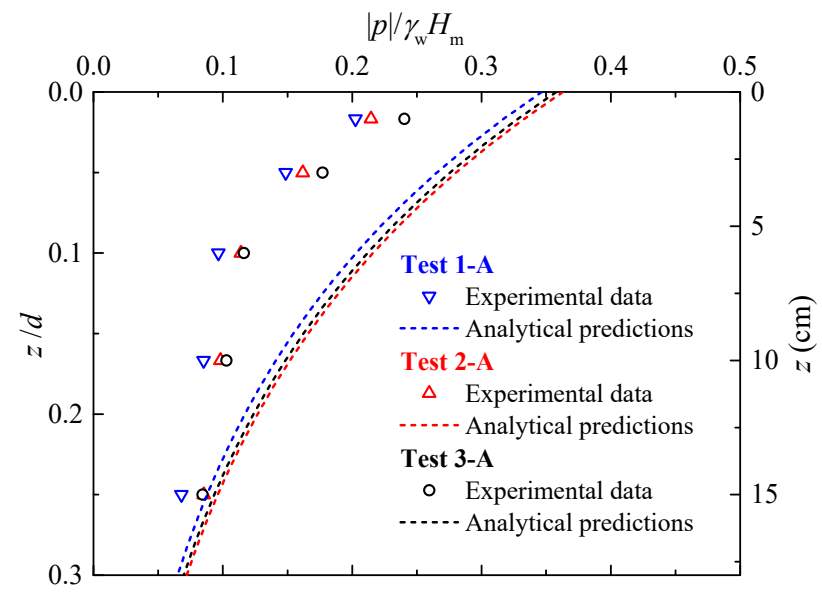

(c)

Figure 12. Comparisons of the vertical distributions of pore-pressure amplitude between experimental results and analytical predictions for various test series: (a) Test $C$ (non-breaking wave); (b) Test $B$ (incipient-breaking wave); (c) Test A (broken wave) $\left(|p|=p_{\mathrm{m}} / 2\right)$. 


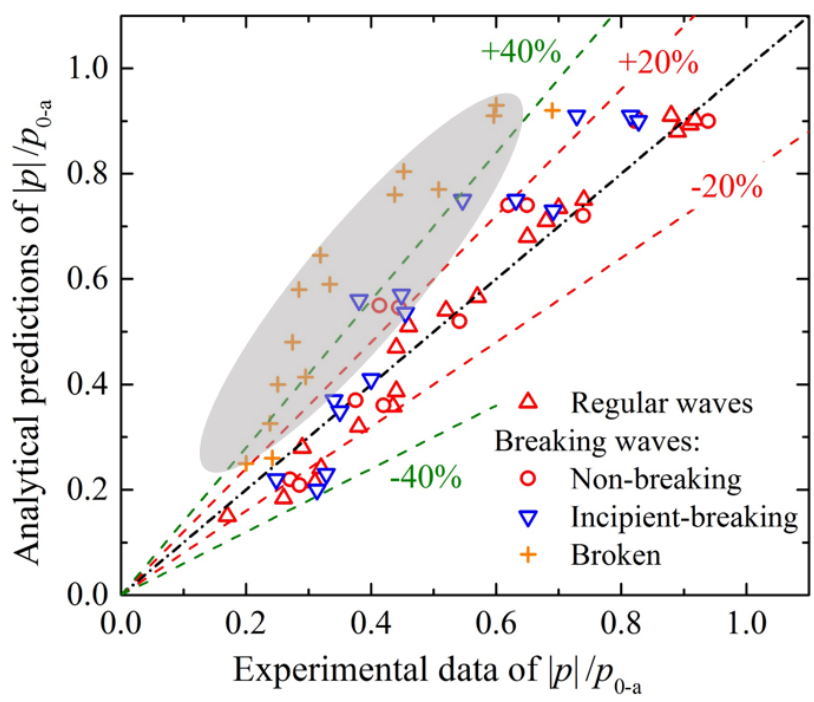

Figure 13. Comparisons of the transient pore-pressure amplitude between experimental results and analytical solutions under non-breaking regular waves and breaking-waves.

To distinctly assess the deviation of the breaking-wave induced pore-pressure from the analytical predictions, the variations of $|p|_{\mathrm{e}} /|p|_{\mathrm{a}}$ for various wave conditions are given in Figure 14, in which $|p|_{\mathrm{e}}$ and $|p|_{\mathrm{a}}$ are the experimental data and analytical predictions with the Yamamoto solution for the pore-pressure amplitude, respectively. It should be noted that certain derivations between the experimental data and analytical predictions still exist in a relatively deeper layer (e.g., $z=0.15 \mathrm{~m}$ ), even for the non-breaking regular wave induced pore-pressure amplitude (see Figure 13), this may attribute to the bottom boundary effect in the flume experiments. Therefore, the data points for $z=0.15 \mathrm{~m}$ are not present in Figure 14 to avoid such an effect. A general trend can be identified from this figure, i.e., the values of $|p|_{\mathrm{e}} /|p|_{\mathrm{a}}$ keep decreasing with the development of wave breaking, which highlights the effects of wave energy dissipation on pore-pressure responses. The analytical solution for non-breaking regular waves would overestimate the transient porepressure amplitude for breaking-waves. That is, the analytical solution could provide a conservative prediction while evaluating the potential risk for the safety of submarine foundations under the action of breaking-waves.

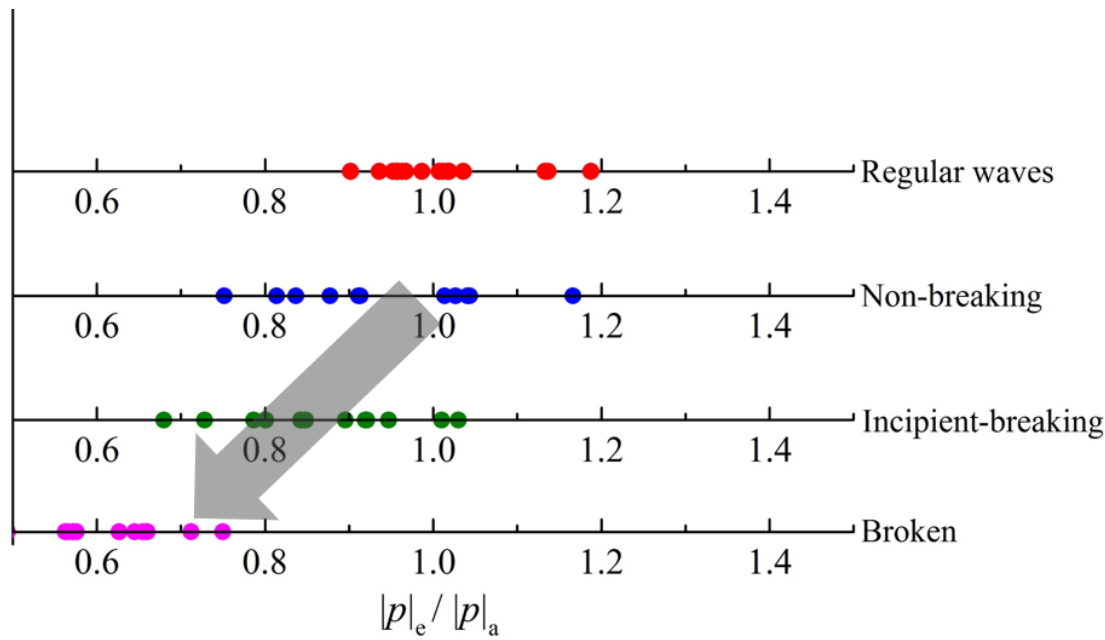

Figure 14. The variation of $|p|_{\mathrm{e}} /|p|_{\mathrm{a}}$ for various stages during wave-breaking. 


\section{Conclusions}

The wave-breaking is a common scenario in coastal surf zones, which may further influence the pore-pressure responses in the porous seabed. In this study, a series of flume tests was carried out to investigate the breaking-wave induced pore-pressure in a finegrained sand-bed. The following conclusions can be drawn from the flume observations and comparative analyses:

(1) A plunging-type of breaking-waves was generated by superimposing a series of longer waves onto the foregoing shorter waves at a specified location in a flume. It was observed that once the shorter waves seemed to be swallowed up by the following longer waves, the breaking of progressive waves occurred suddenly and the wave height was greatly diminished during wave breaking.

(2) Flume observations indicate that both water surface elevations and the corresponding transient pore-pressure responses are featured with irregularity and asymmetry in the process of wave breaking. Fourier spectra are obtained for the breaking waves and those for the pore-pressures, indicating the peak frequencies of the surface waves are generally larger than those of the pore-pressures. As expected, the highfrequency components of superimposing surface waves were hardly detected by the pore-pressure transduces. From time developments of water surface elevations and pore-pressures under breaking waves, the characteristic parameters can be well identified graphically, including the characteristic wave period $\left(T_{\mathrm{w}}\right)$, wave height $\left(H_{\mathrm{m}}\right)$, and the period of transient pore-pressure $\left(T_{\mathrm{p}}\right)$, etc. The measured values of the characteristic time parameters for the pore-pressures are generally larger than those for the wave surface elevations. After wave breaking, the magnitude of transient pore-pressure oscillation was decreased significantly.

(3) The experimental results of the pore-pressure under breaking-waves are compared with the predicted values with the analytical solution by Yamamoto et al. (1978) for non-breaking regular waves. The comparisons indicate that under incipient-breaking or broken waves, the measured values of pore-pressure amplitude are generally smaller than the analytical predictions with equivalent values of the characteristic wave height and wave period. Such deviations between the experimental results and analytical predictions tend to increase with the time development of wave breaking, which could be attributed to the wave energy dissipation during wave breaking.

Author Contributions: Conceptualization, F.G. and C.L.; experiments and data analyses, C.L., F.G., and L.Y.; writing-original draft, C.L.; writing-review and editing, F.G., C.L., and L.Y.; supervision, F.G. All authors have read and agreed to the published version of the manuscript.

Funding: This research is financially supported by the China National Science Fund for Distinguished Young Scholars (11825205), the Strategic Priority Research Program (Type-B) of Chinese Academy of Sciences (XDB22030000).

Institutional Review Board Statement: Not applicable.

Informed Consent Statement: Not applicable.

Data Availability Statement: The experimental data supporting this study are provided within this paper.

Acknowledgments: Technical assistance in the flume test preparation from Fulin Zhang is greatly acknowledged.

Conflicts of Interest: The authors declare no conflict of interest. 


\section{Notations:}

\begin{tabular}{|c|c|}
\hline$c$ & Phase velocity of the wave \\
\hline$c^{\prime}$ & Coefficient in Equation (5) \\
\hline$c_{\mathrm{g}}$ & Group velocity of a wave train \\
\hline$d^{0}$ & Thickness of the sand bed \\
\hline$d_{10}$ & Effective size of sand grains \\
\hline$d_{50}$ & Mean size of sand grains \\
\hline$D_{\mathrm{r}}$ & Relative density of the sand \\
\hline$e$ & Void ratio of the sand \\
\hline E & Energy density \\
\hline$f$ & Frequency \\
\hline$g$ & Gravitational acceleration \\
\hline G & Shear modulus of the soil \\
\hline$h$ & Water depth \\
\hline$H$ & Wave height \\
\hline$H_{0}$ & Wave height of the initially generated waves near the wave maker \\
\hline$H_{\mathrm{m}}$ & Wave height of the breaking-wave (see Figure 9) \\
\hline$i$ & Imaginary number \\
\hline$k_{\mathrm{s}}$ & Coefficient of permeability of the sand \\
\hline$K^{\prime}$ & Apparent bulk modulus of the pore-fluid \\
\hline$l_{\mathrm{b}}$ & Distance between the flume inlet and the breaking location \\
\hline$L$ & Wavelength \\
\hline$m$ & Coefficient in Equation (5) \\
\hline$n$ & Soil porosity of the sand \\
\hline$n_{\mathrm{w}}$ & Coefficient in Equation (1) \\
\hline$p$ & Transient pore-pressure in the sand-bed \\
\hline$p_{0-\mathrm{a}}$ & Theoretical prediction of the wave pressure amplitude at the sand-bed surface \\
\hline$p_{\mathrm{m}}$ & Oscillation magnitude of transient pore-pressure (see Figure 9) \\
\hline$|p|$ & Transient pore-pressure amplitude at a certain soil depth \\
\hline$|p|_{\mathrm{a}}$ & Analytical prediction of the pore-pressure amplitude \\
\hline$|p|_{\mathrm{e}}$ & Measured value of the pore-pressure amplitude in the flume tests \\
\hline$P_{\mathrm{b}}^{\prime}$ & Wave pressure fluctuation at the sand-bed surface \\
\hline$s$ & Specific gravity of the sand grains \\
\hline$S_{\mathrm{r}}$ & Degree of saturation of the sand \\
\hline$t$ & Time \\
\hline$t_{0}$ & Propagation time of the firstly generated wave \\
\hline$t_{\mathrm{i}}$ & The time when the following longer waves were generated \\
\hline$T$ & Wave period \\
\hline$T_{0}$ & Wave period of the firstly generated wave \\
\hline$T_{\mathrm{i}}$ & Wave period of the following wave generated at time $t_{\mathrm{i}}$ \\
\hline$T_{\mathrm{w}}, t_{\mathrm{w}}$ & Time parameters of the breaking-wave (see Figure 9) \\
\hline$T_{\mathrm{p}}, t_{\mathrm{p}}$ & Time parameters of the transient pore-pressure (see Figure 9) \\
\hline$z$ & Soil depth calculated from the mudline \\
\hline$\lambda$ & Wave number \\
\hline$\gamma^{\prime}$ & Buoyant unit weight of the sand \\
\hline$\gamma_{w}$ & Unit weight of the water \\
\hline$\omega$ & Angular frequency of the wave \\
\hline$\omega^{\prime}$ & Coefficient in Equation (5) \\
\hline$\omega^{\prime \prime}$ & Coefficient in Equation (5) \\
\hline$v$ & Poisson's ratio of soil \\
\hline$\lambda$ & Coefficient in Equation (5) \\
\hline$\lambda^{\prime \prime}$ & Coefficient in Equation (5) \\
\hline$\alpha$ & Coefficient in Equation (5) \\
\hline$\beta$ & Coefficient in Equation (5) \\
\hline$\eta$ & Free water surface elevation \\
\hline$c_{0}, c_{\mathrm{g} 0}, n_{\mathrm{w} 0}, \lambda_{0}, \omega_{0}$ & Parameters of the firstly generated wave \\
\hline$c_{\mathrm{i}}, c_{\mathrm{gi}}, n_{\mathrm{wi}}, \lambda_{\mathrm{i}}, \omega_{\mathrm{i}}$ & Parameters of the following longer wave generated at time $t_{\mathrm{i}}$ \\
\hline
\end{tabular}

\section{References}

1. Sumer, B.M.; Fredsøe, J.; Christensen, S.; Lind, M.T. Sinking/floatation of pipelines and other objects in liquefied soil under waves. Coast. Eng. 1999, 38, 53-90. [CrossRef]

2. Jeng, D.S.; Seymour, B.; Gao, F.P.; Wu, Y.X. Ocean waves propagating over a porous seabed: Residual and oscillatory mechanisms. Sci. China Ser. E Technol. Sci. 2007, 50, 81-89. [CrossRef]

3. Gao, F.P. Flow-pipe-soil coupling mechanisms and predictions for submarine pipeline instability. J. Hydrodyn. 2017, 29, 763-773. [CrossRef]

4. Qi, W.G.; Shi, Y.M.; Gao, F.P. Uplift soil resistance to a shallowly-buried pipeline in the sandy seabed under waves: Poroelastoplastic modeling. Appl. Ocean Res. 2020, 95, 102024. [CrossRef]

5. Randolph, M.F.; Gourvenec, S. Offshore Geotechnical Engineering; Spon Press: New York, NY, USA, 2011. 
6. Sumer, B.M. Liquefaction Around Marine Structures; World Scientific: Singapore, 2014.

7. Gao, F.P.; Li, J.H.; Qi, W.G.; Hu, C. On the instability of offshore foundations: Theory and mechanism. Sci. China-Phys. Mech. Astron. 2015, 58, 124701. [CrossRef]

8. Jeng, D.-S. Mechanics of Wave-Seabed-Structure Interactions: Modelling, Processes and Applications; Cambridge University Press: Cambridge, UK, 2018.

9. Celli, D.; Li, Y.; Ong, M.C.; Di Risio, M. Random wave-induced momentary liquefaction around rubble mound breakwaters with submerged berms. J. Mar. Sci. Eng. 2020, 8, 338. [CrossRef]

10. Yamamoto, T.; Koning, H.L.; Sellmeijer, H.; Hijum, E.V. On the response of a poro-elastic bed to water waves. J. Fluid Mech. 1978, 87, 193-206. [CrossRef]

11. Madsen, O.S. Wave-induced pore-pressures and effective stresses in a porous bed. Geotechnique 1978, 28, 377-393. [CrossRef]

12. Hsu, J.R.C.; Jeng, D.-S. Wave-induced soil response in an unsaturated anisotropic seabed of finite thickness. Int. J. Numer. Anal. Methods Geomech. 1994, 18, 785-807. [CrossRef]

13. Mase, H.; Sakai, T.; Sakamoto, M. Wave-induced porewater pressures and effective stresses around breakwater. Ocean Eng. 1994, 21, 361-379. [CrossRef]

14. Cheng, L.; Sumer, B.M.; Fredsoe, J. Solution of pore pressure buildup due to progressive waves. Int. J. Numer. Anal. Meth. GeoMech. 2001, 25, 885-907. [CrossRef]

15. Zhang, C.; Sui, T.T.; Zheng, J.H.; Xie, M.X.; Nguyen, V.T. Modelling wave-induced 3D non-homogeneous seabed response. Appl. Ocean Res. 2016, 61, 101-114. [CrossRef]

16. Tsui, Y.T.; Helfrich, S.C. Wave-induced pore pressures in submerged sand layer. J. Geotech. Eng. 1983, 109, 603-618. [CrossRef]

17. Liu, B.; Jeng, D.-S.; Ye, G.L.; Yang, B. Laboratory study for pore pressures in sandy deposit under wave loading. Ocean Eng. 2015, 106, 207-219. [CrossRef]

18. Qi, W.G.; Li, C.F.; Jeng, D.S.; Gao, F.P.; Liang, Z. Combined wave-current induced excess pore-pressure in a sandy seabed: Flume observations and comparisons with theoretical models. Coast. Eng. 2019, 147, 89-98. [CrossRef]

19. Jeng, D.-S. Wave-induced sea floor dynamics. Appl. Mech. Rev. 2003, 56, 407-429. [CrossRef]

20. Jeng, D.-S. Porous Models for Wave-Seabed Interactions; Springer: Heidelberg, Germany, 2013.

21. Galvin, C.J. Breaker type classification on three laboratory beaches. J. Geophys. Res. 1968, 73, 3651-3659. [CrossRef]

22. Basco, D.R.; Asce, M.A. Qualitative Description of Wave Breaking. J. Waterw. Port Coast. Ocean Eng. 1985, 111, 171-188. [CrossRef]

23. Zelt, J.A. The run-up of nonbreaking and breaking solitary waves. Coast. Eng. 1991, 15, 205-246. [CrossRef]

24. Ting, F.C.K.; Kirby, J.T. Observation of undertow and turbulence in a laboratory surf zone. Coast. Eng. 1994, 24, 51-80. [CrossRef]

25. Ting, F.C.K.; Kirby, J.T. Dynamics of surf-zone turbulence in a strong plunging breaker. Coast. Eng. 1995, 24, 177-204. [CrossRef]

26. Chang, K.A.; Liu, P.L.-F. Velocity, acceleration and vorticity under a breaking wave. Phys. Fluids 1998, 10, 327-329. [CrossRef]

27. Shin, S.; Cox, D. Laboratory observations of inner surf and swash-zone hydrodynamics on a steep slope. Cont. Shelf Res. 2006, 26, 561-573. [CrossRef]

28. Calabrese, M.; Buccino, M.; Pasanisi, F. Wave breaking macrofeatures on a submerged rubble mound breakwater. J. Hydro-Environ. Res. 2008, 1, 216-225. [CrossRef]

29. Moragues, M.V.; Clavero, M.; Losada, M.A. Wave Breaker Types on a Smooth and Impermeable 1:10 Slope. J. Mar. Sci. Eng. 2020, 8, 296. [CrossRef]

30. Corvaro, S.; Mancinelli, A.; Brocchini, M.; Seta, E.; Lorenzoni, C. On the wave damping due to a permeable seabed. Coast. Eng. 2010, 57, 1029-1041. [CrossRef]

31. Lin, P.; Liu, P.L.-F. A numerical study of breaking waves in the surf zone. J. Fluid Mech. 1998, 359, 239-264. [CrossRef]

32. Zhang, Q.; Liu, P.L.-F. A numerical study of swash flows generated by bores. Coast. Eng. 2008, 55, 1113-1134. [CrossRef]

33. Lakehal, D.; Liovic, P. Turbulence structure and interaction with steep breaking waves. J. Fluid Mech. 2011, 674, 522-577. [CrossRef]

34. Zijlema, M.; Stelling, G.; Smit, P. SWASH: An operational public domain code for simulating wave fields and rapidly varied flows in coastal waters. Coast. Eng. 2011, 58, 992-1012. [CrossRef]

35. Jeng, D.-S.; Zhang, H. An integrated three-dimensional model of wave-induced pore pressure and effective stresses in a porous seabed: II. breaking waves. Ocean Eng. 2005, 32, 1950-1967. [CrossRef]

36. Ulker, M.B.C.; Rahman, M.S.; Guddati, M.N. Breaking wave-induced response and instability of seabed around caisson breakwater. Int. J. Numer. Anal. Methods Geomech. 2012, 36, 362-390. [CrossRef]

37. Ye, J.H.; Jeng, D.-S.; Liu, P.L.-F.; Chan, A.H.C.; Wang, R.; Zhu, C.Q. Breaking wave-induced response of composite breakwater and liquefaction in seabed foundation. Coast. Eng. 2014, 85, 72-86.

38. Sarpkaya, T.; Isaacson, M. Mechanics of Wave Forces on Offshore Structures; Van Nostrand Reinhold Company: New York, NY, USA, 1981.

39. Niu, J.; Xu, J.; Dong, P.; Li, G. Pore water pressure responses in silty sediment bed under random wave action. Sci. Rep. 2019, 9, 11685. [CrossRef]

40. Biot, M.A. General theory of three-dimensional consolidation. J. Appl. Phys. 1941, 12, 155-164. [CrossRef] 